\title{
Paper
}

\section{Prognostic factors associated with bladder tumours}

P H Abeygunasekaral ${ }^{1}$ R Perera ${ }^{1} S$ A S Goonawardene ${ }^{2}$ M V C De Silva ${ }^{1}$

\begin{abstract}
Introduction: Transurethrally resected bladder tumours are at risk of recurrence and progression to invasive cancer.

Objectives: To assess factors which predict recurrence and progression in bladder tumours.

Methods: This retrospective analysis included 192 patients with bladder tumours treated at a urology unit in a tertiary care hospital in Sri Lanka with a mean follow up of 63.7 months $(\mathrm{SD} \pm 18.8$, range 37-99 months). Follow up details were obtained from clinic records. Factors which were analyzed as possible predictors of tumour recurrence and progression included the tumour growth pattern, mitotic count, necrosis, lamina propria invasion, muscularis propria invasion, lympho-vascular invasion, focal pleomorphic areas, squamous differentiation, glandular differentiation, adjacent carcinoma in-situ and the tumour grade. Cox univariate and multivariate analysis was done together with a Kaplan Meier survival analysis.
\end{abstract}

Results and Conclusion: In the univariate analysis the tumour stage $(\mathrm{p}=0.042)$ and lamina propria invasion ( $p=0.031)$ were the only significant predictors of tumour recurrence. In multivariate analysis the most significant independent factor associated with tumour recurrence was lamina propria invasion ( $p=0.02)$, In Kaplan Meier survival analysis there was a significant difference in recurrence free survival (RFS) between the low grade urothelial carcinoma and the invasive group within the WHO/ISUP classification ( $\log$ rank 4.78, $\mathrm{p}=0.0287$ ). Only six cases progressed in stage or grade during the follow up period.

(Key words: Bladder carcinoma, prognostic factors)

${ }^{1}$ Department of Pathology, Faculty of Medicine, Colombo, ${ }^{2}$ National Hospital of Sri Lanka

Correspondence: P H Abeygunasekara, email: priyankaabey@yahoo.com 


\section{Introduction}

Bladder cancers account for $1 \%$ of all cancers in Sri Lanka (1). Transurethrally resected bladder tumours are at risk of recurrence and progression to invasive cancer (2). Therefore, information is necessary to identify patients at risk of recurrence and progression. Identifying the prognostic factors that determine the risk in each patient for recurrence and progression remains a subject of extensive research.

Most studies have assessed the prognostic value of different clinico-pathological variables such as stage $(3)$, grade $(3)$, size $(3,4,5)$ tumour multiplicity $(3,4,5)$, location $(5)$, configuration (3), microvessel density $(6,7)$, associated carcinoma in-situ (5) and recurrence at check cystoscopy at the first three months (5).

Prognostic factors which predict tumour recurrence and progression have not been studied previously in Sri Lanka. Thus the objective was to determine factors which predict recurrence and progression of bladder tumours in a local setting.

\section{Methods}

A retrospective analysis of histological assessment performed on 262 patients diagnosed with bladder tumours who underwent surgery in a urology unit at a tertiary care hospital in Sri
Lanka from September 1996 to December 2001 was done. Of these, 50 cases with a previous diagnosis of bladder tumour at presentation and 20 cases without demographic data were excluded from the study and the final study population consisted of 192 cases with primary bladder tumour.

Out of these 192 cases, $87.6 \%(n=169)$ were males and $12.4 \%(n=23)$ were females (male: female ratio of $7: 1)$. The mean age of the study group was 62 years ( $\mathrm{SD} \pm 12.6$, range 26 to 91$)$. These cases were followed up for tumour recurrence and progression until December 2004. The mean follow up period was 63.7 months $(\mathrm{SD} \pm$ 18.8 , range 37 to 99 months).

All the patients had transurethral resections of the bladder tumours. The specimens had been routinely processed and 4-5 micron thick sections were stained with haematoxylin and eosin and examined under light microscopy. The slides of all tumours were re-assessed. All transitional cell carcinomas were graded using the WHO/ISUP system.

The tumours were categorized into following subgroups according to the WHO/ISUP system (11): Papilloma, Papillary urothelial neoplasm of low malignant potential (PUNLMP) (Fig. 1\& 2), Low-grade papillary urothelial carcinoma (LGPUC) (Fig. 3 \& 4), 
High-grade papillary urothelial carcinoma (HGPUC) and Invasive tumours (lamina propria or muscularis propria invasive) (Fig. $5 \& 6$ ).

The invasive tumours were further categorised

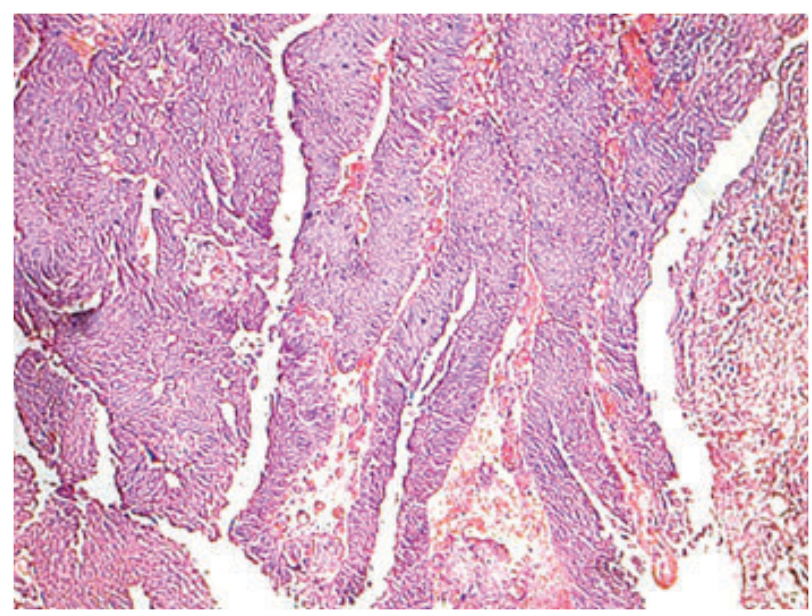

Fig 1. Papillary urothelial neoplasm of low malignant potential - PUNLMP (H\& E x100)

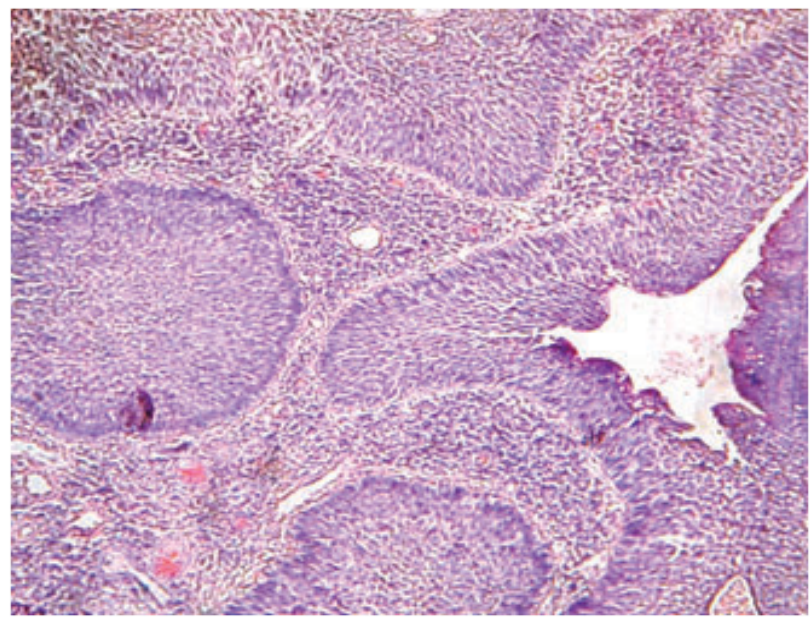

Fig 3. Non-invasive, low grade papillary urothelial carcinoma (H \& E x100). to low-grade and high-grade tumours based on their morphology analogous to the scheme used for grading of non invasive lesions.

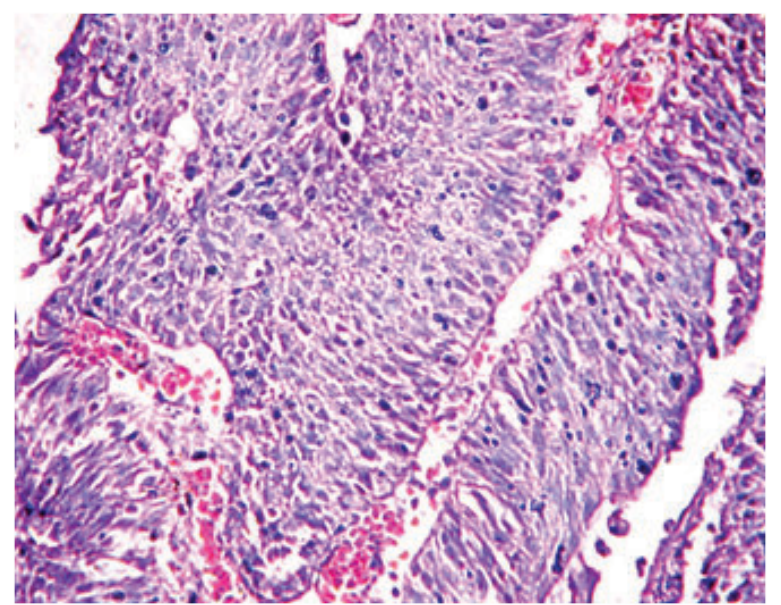

Fig 2. Papillary urothelial neoplasm of low malignant potential PUNLMP (H\&E x 400)

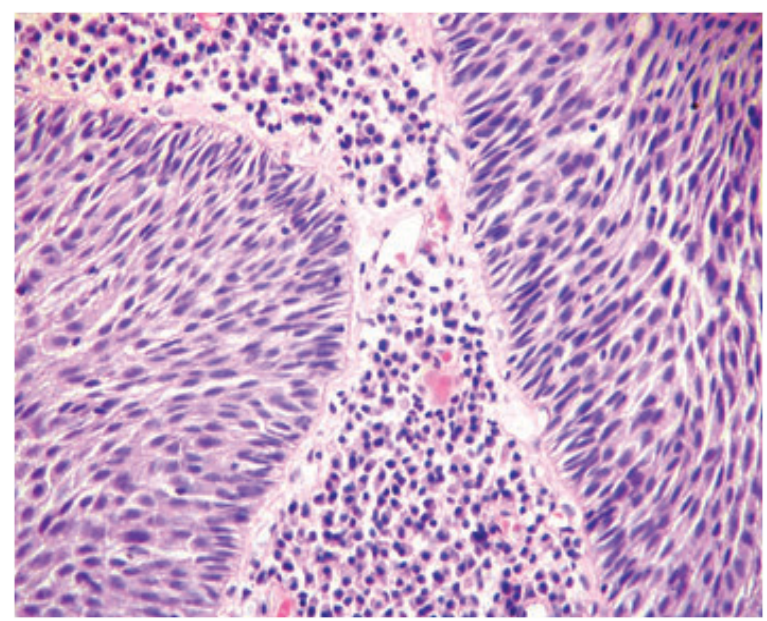

Fig 4. Non-invasive low grade papillary urothelial carcinoma (H \& E x 400). 


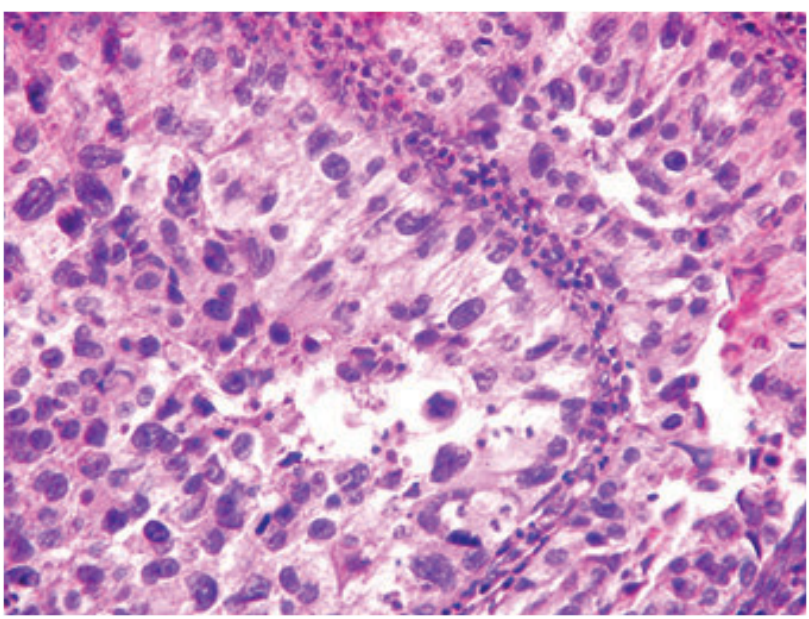

Fig 5. Invasive high grade urothelial carcinoma with lamina propria invasion (H \& E x 100)

The histological features analyzed included mitotic count, pattern of growth (categorized as papillary, nodular, mixed papillary predominant, mixed nodular predominant and infiltrating), and the presence or absence of necrosis, lympho-vascular invasion, highly atypical areas admixed with low grade malignancy, carcinoma in situ, lamina propria involvement, muscle involvement, squamous and glandular differentiation.

Mitotic activity was assessed as follows: The mitoses were counted in the most cellular and pleomorphic areas of the tumours using an Olympus (model BX50) conference microscope. The count was obtained in four sets of 10 consecutive high power fields $(\mathrm{x} 400)$ and the mean mitotic count was calculated for each tumour. These were further sub classified to mitotic count of $\geq 5 / 10 \mathrm{HPF}$ and $<5 / 10 \mathrm{HPF}$.

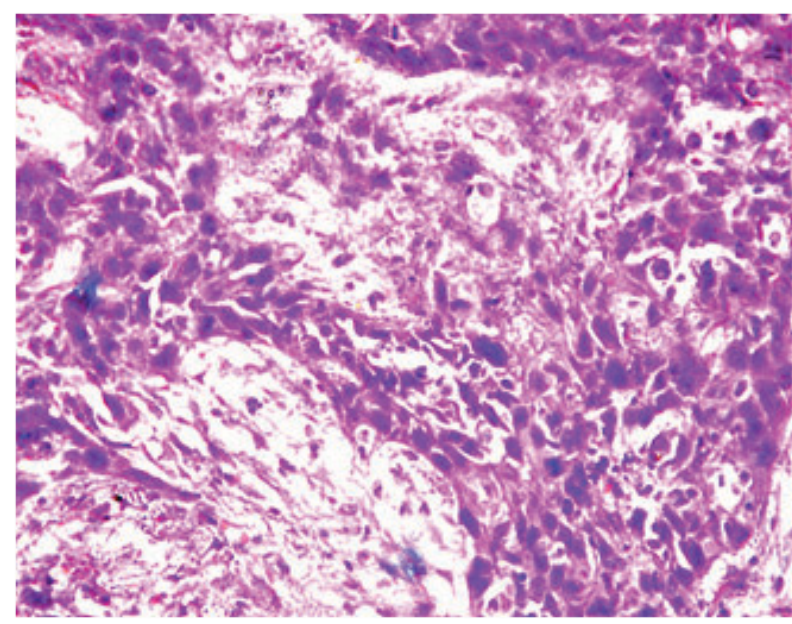

Fig 6. Invasive high grade urothelial carcinoma with lamina propria invasion (H \& E x 400).

The presence of highly atypical areas admixed with low grade malignancy was defined as atypical areas containing cells with nuclear grade 3 or 4 (with hyperchromasia and pleomorphism) with or without bizarre mitoses, clearly seen separately from the surrounding tissue. This atypia had to be recognizable under medium power (x 100)

The presence of lamina propria involvement was further subdivided into focal and diffuse involvement. One or two foci of lamina propria involvement was defined as focal involvement. Multifocal invasion was defined as diffuse involvement.

The presence of muscle involvement was defined as the invasion the muscularis propria by the tumour. Only thick bundles of smooth muscle present in the biopsy were considered as muscularis propria. Involvement 
of the muscularis propria was designated as pT2. If the muscle was not included in the biopsy it was thus stated.

Tumour size and multiplicity were not evaluated in the study due to lack of clinical information in some of the cases. Follow up details were obtained from the request forms and clinic records.

Tumour recurrence was defined as re-emergence of the tumour with histological confirmation after complete removal. Only the tumours which recurred at least one month following initial surgery were considered true recurrences. The biopsies $(n=11)$ which were done in less than one month after first diagnosis were excluded from the study. Recurrent tumours were analyzed and graded according to the WHO/ISUP grading system.

Tumour progression was defined as the development of high-grade malignancy or lamina proprial or muscle invasive disease in superficial tumours. None of the patients died of the tumour during the study period.

Data was entered to a SPSS programme 10.0 (SPSS for windows 10, SPSS inc.). Analysis for recurrence and progression was only done for transitional cell carcinomas. Factors potentially affecting tumour recurrence and progression were assessed. When analysing the muscularis propria invasion, the tumours which lacked muscularis propria on biopsy were excluded.

Univariate and multivariate analysis were done using the Cox regression and Kaplan Meier survival analysis. The log rank test was used to compare recurrence free survival (RFS) between different groups in Kaplan Meier survival analysis. Recurrence free survival was calculated from the date of the first diagnosis until the date of the first recurrence. In tumours without recurrence the whole follow up period was taken as recurrence free survival. Significance was defined as a $\mathrm{p}$ value equal or less than 0.05 . All $\mathrm{p}$ values were 2 sided with odd ratios and $95 \%$ confidence intervals.

\section{Results}

There were 174 (90.6\%) transitional cell carcinomas. The majority of the tumours were invasive neoplasms ( $\mathrm{n}=111,63.8 \%)$. The commonest non-invasive papillary transitional cell carcinoma was low-grade papillary transitional cell carcinoma $(n=52)$. There were only three cases of PUNLMP and eight cases of high-grade urothelial carcinoma (non invasive). There were no papillomas.

The tumour characteristics which were used as potential prognostic factors for tumour recurrence and progression and their association with tumour recurrence are shown in table 1. 
With the chi-square test, factors significantly associated with tumour recurrence were lamina propria invasion $(\mathrm{p}=0.025$, odds ratio 2.449, CI 1.1-5.45)), tumour stage $(p=0.040)$

and the WHO/ISUP grade $(p=0.05)$ of the original tumour. The recurrent tumours and the time of recurrence are shown in table 2.

Table 1: Assessment of potential prognostic factors with local recurrence (p values are for chi-square test)

\begin{tabular}{|c|c|c|c|c|c|}
\hline Prognostic factor & Number & Percentage & Recurrence & p value & Odds ratio $(\mathrm{CI})$ \\
\hline Growth pattern & & & & 0.602 & \\
\hline Papillary & 68 & 35.1 & $14 / 68$ & & \\
\hline Nodular & 56 & 29.2 & $14 / 56$ & & \\
\hline Mixed-Papillary & 28 & 14.6 & $10 / 28$ & & \\
\hline predominant & & & & & \\
\hline $\begin{array}{l}\text { Mixed-Nodular } \\
\text { predominant }\end{array}$ & 25 & 13 & $7 / 25$ & & \\
\hline Infiltrating & 15 & 7.8 & $3 / 15$ & & \\
\hline Mitotic count & & & & 0.133 & 1.667 \\
\hline$\geq 5$ & 102 & 53.1 & $30 / 102$ & & $(0.853-.255)$ \\
\hline$<5$ & 90 & 46.4 & $18 / 90$ & & \\
\hline Necrosis & & & & 0.530 & 1.288 \\
\hline Present & 38 & 19.8 & $11 / 38$ & & $(0.583-.846)$ \\
\hline Absent & 154 & 80.2 & $37 / 154$ & & \\
\hline Lamina propria & & & & 0.025 & 2.449 \\
\hline invasion & & & & & $(1.1-5.45)$ \\
\hline Present & 131 & 68.2 & $39 / 131$ & & \\
\hline Absent & 61 & 32 & $9 / 61$ & & \\
\hline Muscularis propria & & & & 0.685 & 0.85 \\
\hline invasion & & & & & $(0.387-.866)$ \\
\hline Present & 66 & 34.4 & $15 / 66$ & & \\
\hline Absent & 70 & 36.5 & $18 / 70$ & & \\
\hline Not included & 56 & 29.2 & $15 / 56$ & & \\
\hline $\begin{array}{l}\text { Lymphovascular } \\
\text { invasion }\end{array}$ & & & & 0.266 & $\begin{array}{l}2.33 \\
(0.503-10.821)\end{array}$ \\
\hline Present & 7 & 3.6 & $3 / 7$ & & \\
\hline Absent & 185 & 96.4 & $45 / 185$ & & \\
\hline Tumour stage & & & & 0.040 & 0.611 \\
\hline $\mathrm{pTa}$ & 59 & 30.7 & $9 / 59$ & & $(0.196-.901)$ \\
\hline pT1 & 66 & 34.4 & $23 / 66$ & & \\
\hline pT2 & 67 & 34.5 & $16 / 67$ & & \\
\hline $\begin{array}{l}\text { Squamous } \\
\text { differentiation }\end{array}$ & & & & 0.391 & $\begin{array}{l}1.13 \\
(0.288-.456)\end{array}$ \\
\hline Present & 23 & 12 & $4 / 23$ & & \\
\hline Absent & 160 & 83.3 & $41 / 160$ & & \\
\hline
\end{tabular}




\begin{tabular}{|c|c|c|c|c|c|}
\hline $\begin{array}{l}\text { Glandular } \\
\text { differentiation } \\
\text { Present } \\
\text { Absent }\end{array}$ & $\begin{array}{l}11 \\
181\end{array}$ & $\begin{array}{l}5.7 \\
94.3\end{array}$ & $\begin{array}{l}3 / 11 \\
45 / 181\end{array}$ & 0.858 & $\begin{array}{l}1.13 \\
(0.288-.456)\end{array}$ \\
\hline $\begin{array}{l}\text { Focal pleomorphic } \\
\text { areas } \\
\text { Present } \\
\text { Absent } \\
\end{array}$ & $\begin{array}{l}5 \\
187 \\
\end{array}$ & $\begin{array}{l}2.6 \\
97.4 \\
\end{array}$ & $\begin{array}{l}1 / 5 \\
47 / 187 \\
\end{array}$ & 0.794 & $\begin{array}{l}0.75 \\
(0.081-6.83)\end{array}$ \\
\hline $\begin{array}{l}\text { Carcinoma in situ } \\
\text { Present } \\
\text { absent }\end{array}$ & $\begin{array}{l}9 \\
183 \\
\end{array}$ & $\begin{array}{l}4.7 \\
95.3 \\
\end{array}$ & $\begin{array}{l}3 / 9 \\
45 / 183 \\
\end{array}$ & 1.533 & $0.368-6.383$ \\
\hline $\begin{array}{l}\text { WHO/ISUP grade } \\
\text { (non invasive) } \\
\text { PUNLMP } \\
\text { LGPUC } \\
\text { HGPUC }\end{array}$ & $\begin{array}{l}3 \\
52 \\
08\end{array}$ & & $\begin{array}{l}1 / 3 \\
8 / 52 \\
0 / 8\end{array}$ & 0.05 & \\
\hline
\end{tabular}

Note: Odds ratios are only given for $2 \times 2$ tables

Table 2: The time interval of recurrences

\begin{tabular}{|l|l|l|l|}
\hline Recurrence & Number & $\begin{array}{l}\text { Mean time interval } \\
\text { (months) }\end{array}$ & Standard Deviation \\
\hline First recurrence & 48 & 47.8 & $+/-28.69$ \\
\hline Second recurrence & 22 & 12.12 & $+/-7.43$ \\
\hline Third recurrence & 10 & 21.3 & $+/-7.2$ \\
\hline Fourth recurrence & 7 & 27.8 & $+/-4.71$ \\
\hline Fifth recurrence & 5 & 34.3 & $+/-3.2$ \\
\hline Sixth recurrence & 4 & 38 & $+/-3.56$ \\
\hline Seventh recurrence & 1 & 38 & \\
\hline
\end{tabular}

Table 3. Univariate analysis of prognostic factors, hazard ratios, $p$ values and confidence intervals

\begin{tabular}{|l|l|l|l|}
\hline Variable & Hazard ratio & p value & CI \\
\hline Growth pattern & 1 & 0.575 & \\
Papillary & 1.238 & & \\
Nodular & 1.93 & 0.572 & $0.590-2.6$ \\
Mixed papillary predom: & 1.48 & 0.112 & $0.857-4.349$ \\
Mixed nodularpredom: & 0.987 & 0.396 & $0.598-3.671$ \\
Infiltrating & 0.983 & $0.284-3.435$ \\
\hline
\end{tabular}




\begin{tabular}{|c|c|c|c|}
\hline $\begin{array}{l}\text { Mitotic count }>\mathbf{5} \\
\text { No } \\
\text { Yes }\end{array}$ & $\begin{array}{l}1 \\
1.579\end{array}$ & 0.126 & $0.880-2.834$ \\
\hline $\begin{array}{l}\text { Necrosis } \\
\text { No } \\
\text { Yes }\end{array}$ & $\begin{array}{l}1 \\
1.254\end{array}$ & 0.510 & $0.639-2.461$ \\
\hline $\begin{array}{l}\text { Lamina propria invasion } \\
\text { No } \\
\text { Yes }\end{array}$ & $\begin{array}{l}1 \\
2.22 \\
\end{array}$ & 0.031 & $1.075-4.584$ \\
\hline $\begin{array}{l}\text { Lamina propria invasion } \\
\text { Focal } \\
\text { Diffuse }\end{array}$ & $\begin{array}{l}1 \\
2.113 \\
\end{array}$ & 0.059 & $0.971-4.599$ \\
\hline $\begin{array}{l}\text { Musuclaris propria invasion } \\
\text { No } \\
\text { Yes }\end{array}$ & $\begin{array}{l}1 \\
0.868 \\
\end{array}$ & 0.686 & $0.437-1.723$ \\
\hline $\begin{array}{l}\text { Invasive grade } \\
\text { Low } \\
\text { High }\end{array}$ & 1.36 & 0.427 & $0.637-2.904$ \\
\hline $\begin{array}{l}\text { Lympho vascular invasion } \\
\text { No } \\
\text { Yes }\end{array}$ & $\begin{array}{l}1 \\
2.02 \\
\end{array}$ & 0.239 & $0.627-6.51$ \\
\hline $\begin{array}{l}\text { Tumour stage } \\
\text { pTa } \\
\text { pT1 } \\
\text { pT2 }\end{array}$ & $\begin{array}{l}1 \\
2.61 \\
1.647 \\
\end{array}$ & $\begin{array}{l}0.042 \\
0.015 \\
0.231 \\
\end{array}$ & $\begin{array}{l}1.207-5.642 \\
0.727-3.729\end{array}$ \\
\hline $\begin{array}{l}\text { Pleomorphic areas } \\
\text { No } \\
\text { Yes }\end{array}$ & $\begin{array}{l}1 \\
0.816 \\
\end{array}$ & 0.840 & $0.113-5.915$ \\
\hline $\begin{array}{l}\text { Squamous differentiation } \\
\text { No } \\
\text { yes }\end{array}$ & $\begin{array}{l}1 \\
0.637\end{array}$ & 0.390 & $0.228-1.779$ \\
\hline $\begin{array}{l}\text { Glandular differentiation } \\
\text { No } \\
\text { Yes }\end{array}$ & $\begin{array}{l}1 \\
1.104 \\
\end{array}$ & 0.869 & $0.343-3.553$ \\
\hline $\begin{array}{l}\text { WHO/ISUP grade } \\
\text { PUNLMP } \\
\text { LGPUC } \\
\text { HGPUC } \\
\text { Invasive }\end{array}$ & $\begin{array}{l}0.897 \\
0.436 \\
0000 \\
1\end{array}$ & $\begin{array}{l}0.214 \\
0.915 \\
0.034 \\
0.977 \\
\end{array}$ & $\begin{array}{l}0.193-6.552 \\
0.202-0.941 \\
0\end{array}$ \\
\hline $\begin{array}{l}\text { Carcinoma in situ } \\
\text { No } \\
\text { Yes }\end{array}$ & $\begin{array}{l}1 \\
1.452\end{array}$ & 0.532 & $0.451-4.672$ \\
\hline
\end{tabular}


The findings in the univariate analysis are shown in table 3. In the univariate analysis the only significant predictors of tumour recurrence were lamina propria invasion $(\mathrm{HR}=2.22, \mathrm{p}=0.031$, CI $1.075,4.584)$ and tumour stage $(p=0.042)$. A significant differencein tumour stage was seen only between pTatumours and pT1 tumours $(\mathrm{HR}=2.61,0.015$, CI 1.207, 5.642). The pattern of invasion of lamina propria, whether focal or diffuse did not significantly affect the recurrence $(\mathrm{HR}=2.113, \mathrm{p}=0.059$, CI $0.971,4.599)$. Muscle invasion was not a significant predictor of recurrence $(H R=0.87, p=0.69)$. The grade of the invasive tumour (low or high grade) did not significantly affect the tumour recurrence.

In the multivariate analysis, the only variable that was significantly associated with tumour recurrence was lamina propria invasion $(p=0.02)$. The tumours with lamina propria invasion were 2.4 times likely to recur than tumours without lamina propria invasion (CI 1.148, 4.974). The tumour growth pattern, mitotic count, necrosis, lympho-vascular invasion, muscularis propria invasion, focal pleomorphic areas, squamous differentiation, glandular differentiation, adjacent CIS, tumour stage and the WHO grade, were not significantly associated with tumour recurrence.

Analysis with Kaplan Meier survival analysis also showed a significant difference between the recurrence free survival of tumours with lamina propria invasion and without lamina propria invasion $(\log$ rank test $=4.97, \mathrm{p}=0.0258)$ (Fig 7).

\section{Progression}

Only six patients had progression in stage or grade during the follow up period.

\section{Recurrence versus tumour grade}

Kaplan Meier survival analysis comparing the recurrence free survival for different WHO/ISUP grades showed a significant log rank test value for all groups (log rank=4.76, $\mathrm{p}=0.0291)$. (Fig. 8). When different curves were compared with $\log$ rank test the only significant difference seen was between the low grade urothelial carcinoma and the invasive group (log rank 4.78, $\mathrm{p}=0.0287$ ) There were eight high grade transitional cell carcinomas in the study none of which recurred during the follow up period. Three PUNLMP's were present in the study and one case recurred during the follow up period.

A comparison of the recurrence free survival between different categories of WHO/ISUP grade with log rank test and $\mathrm{p}$ values is shown in table 4. 


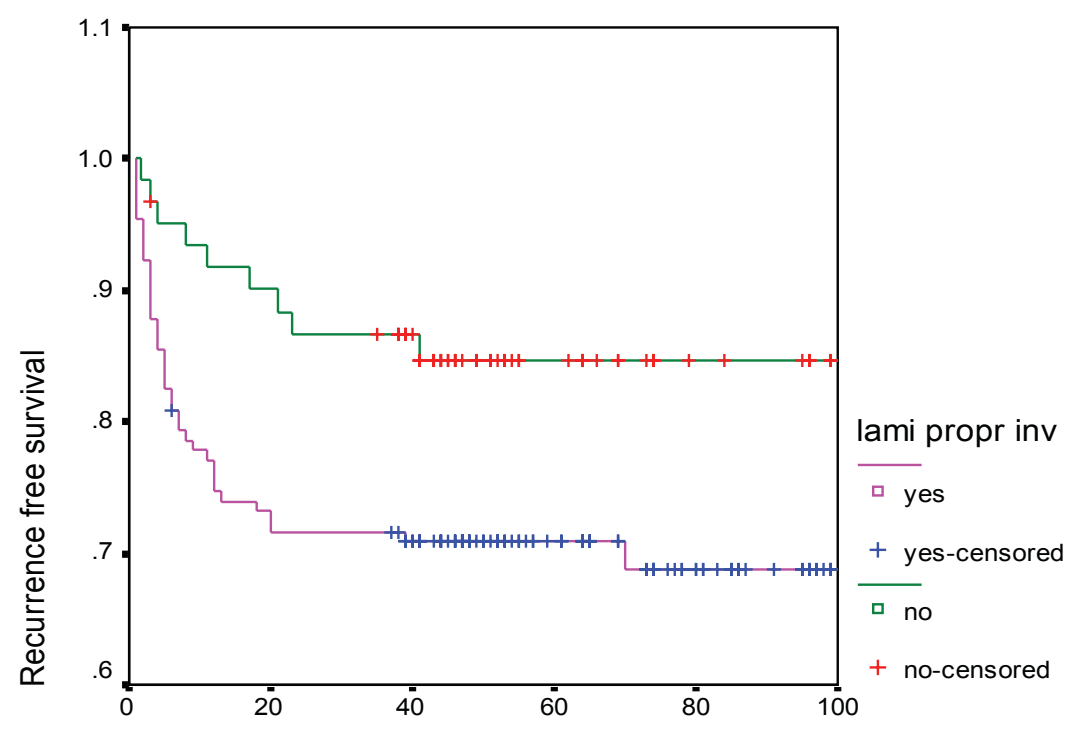

Months from orig $\mathrm{dx}$ to rec1

Fig. 7. Kaplan -Meier plot for recurrence free survival comparing tumours with lamina propria invasion and without lamina propria invasion. The log rank test between the two curves was $4.97(\mathrm{p}=\mathbf{0 . 0 2 5 8})$.

Note: Censored cases were cases which were not associated with recurrence.

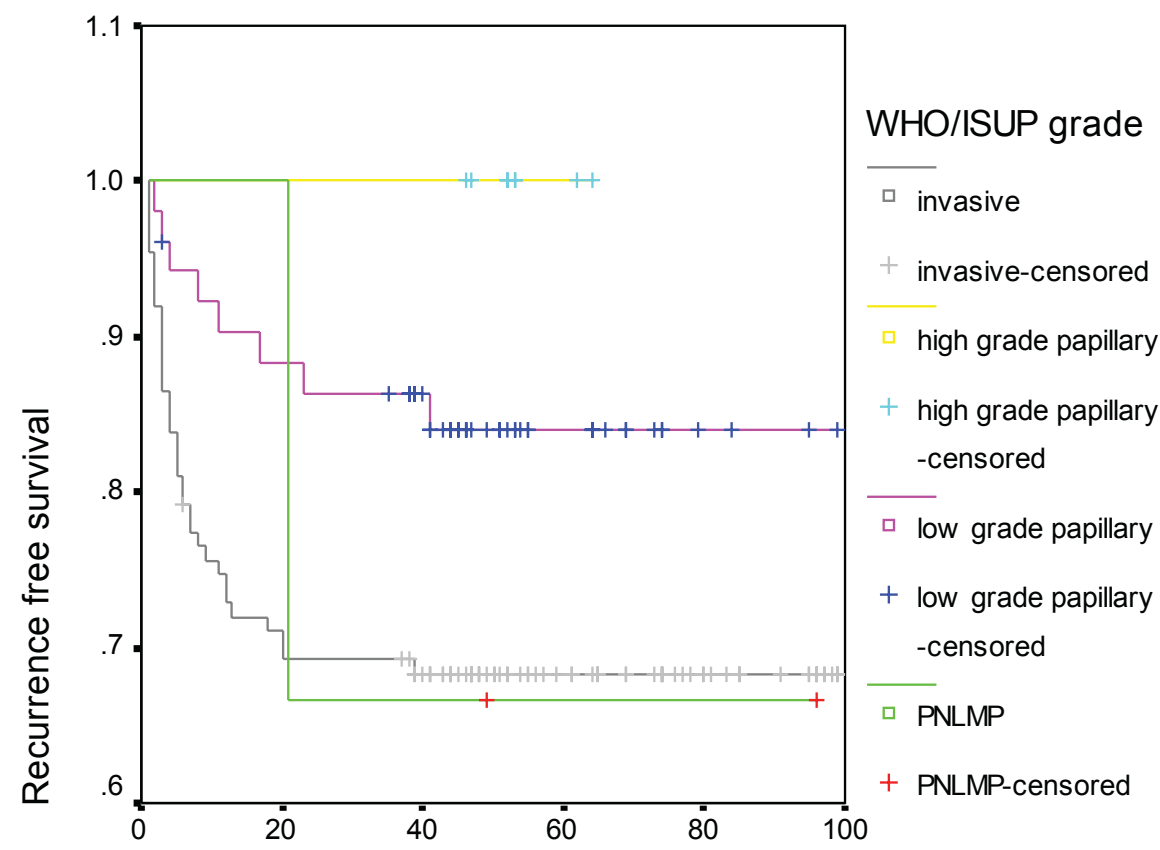

Months from orig $\mathrm{dx}$ to rec1

Fig 8. The Kaplan Meier survival plot for recurrence free survival comparing different subgroups of the WHO/ISUP system. The combined log rank test was $4.76(p=0.0291)$. Comparison between the survival curves by log rank test is shown in table 4.

Note: Censored cases were cases which were not associated with recurrence 
Table 4: Comparison of recurrence free survival by log rank test and its significance in Kaplan Meier survival analysis between the different subgroups of the WHO/ISUP system

\begin{tabular}{|l|l|l|l|}
\hline & PUNLMP & LGPUC & HGPUC \\
\hline LGPUC & $0.51(0.4739)$ & & \\
\hline HGPUC & $2.67(0.1025)$ & $1.38(0.2394)$ & \\
\hline INVASIVE & $0.01(0.9116)$ & $4.78(0.0287)$ & $3.06(0.0802)$ \\
\hline
\end{tabular}

\section{Discussion}

Extensive studies have assessed the prognostic value of different clinico-pathlogical variables as possible predictors of tumour recurrence and progression; eg: tumour stage (3), grade (3), size $(3,4,5)$, multiplicity $(3,4,5)$, location $(5)$, associated CIS (5). Furthermore, several cellular and nuclear markers have been identified as having potential prognostic value (15). Some studies have developed prognostic indexes to predict recurrence $(3,5)$. In this study we used multivariate analysis as opposed to some earlier studies which used univariate analysis.

In 1995 Kurth assessed factors affecting recurrence, progression and death from bladder cancer in 576 cases with bladder tumours. Allard et al (1998) described a prognostic index based on the number of adverse primary tumour characteristics ie: Primary tumour multiplicity, diameter $>3 \mathrm{~cm}$, stage T1 and grade 2 or 3 (3). Their study included 333 patients with primary Ta and
T1 bladder cancer and the mean follow up period was 35.3 months. They found that their simple proposed prognostic index was a strong indicator $\mathrm{f}$ the clinical course of superficial bladder cancer within 3 years of the transurethral bladder resection (TURBT), but the relative value of each of these prognostic factors was not considered.

Dein B. et al (2003) studied 377 cases of bladder tumours randomizing them into six different groups based on different treatment methods and found that on multivariate analysis tumour stage, DNA ploidy, multiplicity, history of recurrence, tumour configuration and type of adjuvant therapy independently affected the rate of recurrence during a mean follow up period of 58 months. They also developed a prognostic index dividing tumours into three risk categories (5).

In our study $25 \%$ of the primary bladder tumours showed at least one recurrence during the mean follow up period of 63.7 months. In 
the univariate analysis lamina propria invasion $(\mathrm{HR}=2.22, \mathrm{p} 0.031, \mathrm{CI} 1.075,4.584)$ and tumour stage $(p=0.042)$ were the only significant predictors of tumour recurrence. For tumour stage this difference was only significant for $\mathrm{pTa}$ and $\mathrm{pT} 1$ tumours (HR 2.61, p=0.015, CI 1.207, 5.642) further signifying the importance of lamina propria invasion for tumour recurrence.

The pattern of invasion of lamina propria whether focal or diffuse, did not significantly affect the recurrence. Muscle invasion was not a significant predictor of recurrence. It is possible that exclusion of 56 cases which lacked the muscularis propria on biopsy resulting in a smaller sample size may have contributed to this negative result. The grade of the invasive tumour (low or high grade) did not significantly affect the recurrence. The tumour growth pattern, mitotic count, necrosis, lymphovascular invasion, focal pleomorphic areas, squamous differentiation, glandular differentiation, adjacent CIS, the WHO/ISUP grade of the tumour were not significant predictors of recurrence.

On multivariate analysis the only significant independent risk factor for tumour recurrence was lamina propria invasion. The tumours with lamina propria invasion had a 2.4 times risk of recurrence than tumours without lamina propria invasion. Kaplan Meier survival analysis also shows a significant difference in recurrence free survival for tumours with and without lamina propria invasion (log rank 4.97, $\mathrm{p}=$ $0.025)$.

Lamina propria invasion and tumour stage are major factors for recurrence in most studies $(3,5)$. However some studies did not show any significant relationship (4). Most studies only studied pTa and pT1 tumours labeling them as superficial tumours $(4,5)$. Tumour stage (ie: presence or absence of lamina propria invasion) has been a significant predictor of recurrence in some studies (5). The terminology used in some studies as 'superficial bladder tumours' is somewhat confusing. Most clinicians also refer to both non invasive (pTa) and lamina propria invasive (pT1) tumours as 'superficial tumours' further confusing the terminology. We believe that the term 'superficial bladder tumours' should be abandoned and be replaced with non invasive (pTa), lamina propria invasive (pT1) and musculairs propria invasive (pT2) tumours as suggested by the International Society of Urological Pathologists (ISUP) conference committee (11).

Tumour grade has not been a significant prognostic factor for recurrence in most studies. A study done by Oosterius in 2002, showed that there was no significant difference in five year recurrence free survival between different groups categorized under WHO/ISUP grading 
system. They only found a difference in progression between PUNLMP and high grade urothelial carcinoma. Samaratunga et al revealed that the WHO/ISUP grading system is an independent predictor of tumour progression $(12,13,14,15)$. Multivariate analysis showed that the most powerful predictors of recurrence, progression and tumour related death were the previous recurrence rate, tumour size, tumour grade and positive 3 month cystoscopy (16).

In 2000 Rodriguez analyzed 1529 cases with primary superficial bladder tumours for a median follow up period of 4.2 years. Multivariate analysis revealed that multiple tumours, tumour size $>3 \mathrm{~cm}$, CIS increased whereas BCG instillations decreased the risk of recurrence. Later he identified three risk groups based on these factors and found a significant difference between the groups for predicting recurrence, progression and mortality (17).

The presence of muscle invasion has not been a predictor of recurrence in our study. Furthermore grading the invasive tumours did not show any significant difference with regard to tumour recurrence. This result is consistent with the study done by Jimenez et al in which he only looked at the grade of muscle invasive tumours with reference to tumour recurrence. He concluded that no additional prognostic information can be obtained by grading the invasive component of muscle invasive carcinoma (18).

$$
\text { However Kruger et al (2003) has }
$$

proposed a two tiered grading system considering tumour heterogeneity by separating the muscle invasive tumours to mixed type (low grade and high grade) and high grade type which showed a significant difference in recurrence free survival (19). Since only six patients progressed in grade or stage during the follow up period it was not possible to draw conclusions with regard to prognostic factors affecting tumour progression from our study.

Sten Holman in 1999 showed that PUNLMP had a significantly low risk of recurrence when compared to low grade urothelial carcinoma thus signifying the importance of differentiating between the two for tumour recurrence (20). Furthermore Pich (2001) identified differences in recurrence and also in expression of oncogenes (p53, c-erb-b2, $\mathrm{BCl} 2)$ and cell proliferative activity between PUNLMP's and low grade urothelial carcinomas (21).

In our study Kaplan Meier survival analysis comparing recurrence free survival of different subgroups of WHO/ISUP classification gives a significant combined log rank test value. However when the log rank test was compared between the groups, the difference was only significant between low grade transitional (noninvasive) cell carcinomas and inasive neoplasms. 
We feel that subcategorizing tumours into an invasive subgroup in the WHO/ISUP classification is an important step forward when grading the bladder tumours. We could not compare recurrence free survival for different grades of non invasive bladder tumours in the WHO/ISUP system as we had relatively small number of cases of non invasive high grade urothelial carcinoma and PUNLMP.

There were only 8 cases of high grade non invasive urothelial carcinoma and none of these cases recurred during the mean follow up period of 67.7 months. Only three cases were categorized as PUNLMP in which only one case recurred. There were no tumours which belonged to the papilloma group. Relatively small number of cases of PUNLMP and high grade urothelial carcinoma made it difficult to interpret the data belonging to these groups.

Several limitations should be considered in the present study. As mentioned, the small sample size and the follow up period are some of the factors. The tumour size and multiplicity could not be analyzed as possible predictors of tumour recurrence due to lack of clinical information. As some of our patients were given adjuvant intravesical therapy the true natural history and tumour grade may have been underestimated. Furthermore grading of the recurrent tumours would have been affected by the therapy to some extent.

\section{Conclusion}

The most important predictor of tumour recurrence in our study was lamina propria invasion. Sub-categorizing lamina propria invasion into focal/diffuse type of invasion or grading the invasive tumours to low and high grade does not provide any additional information for predicting tumour recurrence. The tumour growth pattern, mitotic count, necrosis, lympho-vascular invasion, muscularis propria invasion, focal pleomorphic areas, squamous differentiation, glandular differentiation, adjacent CIS, tumour stage, were not significantly associated with tumour recurrence.

\section{Acknowledgement}

We acknowledge Prof. A. Padmeshwaran, Department of Public Health, University of Kelaniya for assisting with the statistical analysis.

\section{References}

1. Cancer Registry, Cancer incidence in Sri Lanka, 1990, Cancer control programme, Ministry of Health, Sri Lanka.

2. Liang Cheng, Neumann R. M. et al, Cancer heterogeneity and its biological implications in the grading of urothelial carcinoma, Cancer, 2000; 88(7): 1663-70

3. Allard P., Bernard P. et al: The early clinical course of primary Ta and T1 bladder cancer: a proposed prognos- 
tic index: British Journal of Urology 1998; 81: 692-698.

4. Rodriguez FM, Chechile GT et al, Multivariate analysis of the prognostic factors of primary superficial bladder cancer, The Journal of Urology, 2000; 163: 73-78.

5. Dein B. Ali-el, Sarrhan O. et al, Superficial bladder tumours: Analysis of prognostic factors and construction of a predictive index, British Journal of Urology international, 2003; 92(4): 393-399

6. Staropoulos NE Bouropoulos C et al, Prognostic significance of angiogenesis in superficial bladder cancer, International Urology and Nephrology, 2004; $36: 163-167$

7. Hawke CK, Delaauunt B, Microvessel density as a prognostic marker for transitional cell carcinoma of the bladder, British Journal of Urology, 1998; 81: 585-590. 8. Rosai J. Rosai and Ackerman's surgical pathology, 9th edition, 2004, Mosby.

9. Montironi R, Lopez A- Beltran et al, Classification and grading of the non invasiveurothelial neoplasms: recent advances and controversies, Journal of clinical pathology 2003; 56: 91-95.

10. Murphy WM, Beckwith JB, Farrow GM, Tumours of the urinary bladder and related urinary structures, Washington DC; Armed Forces Institute of Pathology, 1994; 211-19.

11. Epstein JJ, Amin B. Mahul, Reuter V. Mostofi F. K. and the bladder consensus conference committee, The World Health Organisation/ International society of
Urological Pathology Consensus classification of urothelial (transitional cell) neoplasms of the urinary bladder, American Journal of Surgical Pathology, 1998; 22(12): 1435-1448.

12. Samaratunga H, Makarov DV, Comparison of WHO/ISUP and WHO classification of non invasive papillary urothelial neoplasms for risk progression, Urology, 2002; 60 (2): 315-319.

13. Oosterhuis JWA, Schapers RFM et al, Histological grading of papillary urothelial carcinoma of the bladder: prognostic value of the $1998 \mathrm{WHO} /$ ISUP classification system and comparison with conventional grading systems, Journal of Clinical pathology, 2002;55: 900905.

14. Mikuz G, The reliability and reproducibility of the different classifications of bladder cancer, Surgical pathology update 2001, 18 th European Congress of Pathology, Berlin: 2001: 114-15.

15. Holmang Sten. et al, Stage progression in Ta papillary urothelial tumours: relationship to grade immunohistochemical expression of tumour markers, mitotic frequency and DNA ploidy; Journal of Urology, 2001; 165: 1124-1130.

16. Kurth KH, Denis L et al Factors affecting recurrence and progression in superficial bladder tumours, European Journal of Cancer, 1995; 31 A: 1840

17. Rodriguez FM, Chechile GT et al, Primary superficial bladder cancer risk groups according to progression, mortality and recurrence, Journal of Urology,. 
2000;164:680-684

18. Jimenez, Rafael E. et al, Grading the invasive component of urothelial carcinoma of the bladder and its relationship with progression free survival, American Journal of Surgical pathology, 2000 July;24(7): 980-987. 19. Kruger $\mathrm{S}$, Thorns $\mathrm{C}$ et al, Prognostic significance of a grading system considering tumour heterogeneity in muscle invasive urothelial carcinoma of the urinary bladder, International Urology and Nephrology, 2003; $35: 169-173$

20. Sten Holmang, Hedelin H., Anderstrom C, Recurrence and progression in low grade papillary urothelialtumours, Journal of Urology, 1999; (162) : 702-707.

21. Pich Achille, Chiusa Luigi et al, Biological differences between noninvasive papillary urothelial neoplasms of low malignant potential an low grade papillary carcinoma of the bladder, American Journal of Surgical Pathology, 2001;25:1528-1533. 